\title{
Hanging On: Reflections on visual reproduction and the UK Abortion Act 1967
}

\author{
Natalie Linda Jones 1
}

Published online: 4 December 2017

(C) The Author(s) 2017. This article is an open access publication

\begin{abstract}
This is a reflection on the visual installation piece, Hanging On, produced collaboratively for the Feminist Legal Studies 'At the Kitchen Table' zine in 2016. The author and co-artist considers the research that informed and helped conceptually drive the aesthetics of the piece, including academic research on abortion within literary aesthetics. How these concepts 'translated' into hands-on artistic practice and physical materials is discussed, including the difficulties and knowledge gained from the process. The author finally considers the benefits of such interdisciplinary, aesthetic encounters within contemporary feminist knowledge production.
\end{abstract}

Keywords Abortion law · Visual art - Aesthetics · Feminist bioethics · Feminist philosophy

Should this limit to what is representable be read as a prohibition against a certain kind of representation? (Butler 2011, 17)

As we have now passed the semi-centennial of the UK Abortion Act 1967 amidst a turbulent climate of UK and transatlantic politics, the potentially precarious nature of certain hard-won gains for women's rights, such as access to abortion, remind us that ground gained through past feminist efforts can be quite swiftly eroded from under our very feet. Indeed, access to abortion has the unfortunate claim to being a legislative act that feminist advocates of 'choice' must continually fight to defend and protect. Within the context of this urgency, art-and in this case specifically visual art-may seem less potent and effective when compared to rigorous scholarship and direct action campaigns in defending safe, legal abortion services for as many women as possible. Yet when the call went out for artists to contribute to the zine 'At the Kitchen Table' for

Natalie Linda Jones

N.Jones.4@warwick.ac.uk

1 University of Warwick, Coventry CV4 7AL, UK 
the $2016 \mathrm{FLaK}$ seminar, ${ }^{1}$ there was a clear acknowledgment of the important role that feminist artists and art might have in moving forward with multifaceted strategies for thinking through the relationship between feminism, legality and knowledge. Such an acknowledgment, or invitation, spoke to a dynamic tradition within feminist approaches to law that valued cross-collaboration, interdisciplinary work and openness.

This was so much the better in the case of Hanging On, a piece created specifically for the zine as a visual artwork reflecting on the historical significance and renewed importance of the UK Abortion Act 1967 (Fig. 1). The final piece itself was created in my role as a co-collaborative visual artist, being based on my academic research as a scholar of English Literature-nineteenth-century literature, no less. Yet while my work as artist and academic may seem far removed from the intricate, specialised knowledge of feminist legal studies, it nonetheless speaks to a productive interdisciplinary crossover in feminist practice and research, not to mention marking emerging trends in the discipline of law and aesthetics. The backbone of Hanging On itself derived from my doctoral project on abortion and aesthetics-abortion as an aesthetic, in fact, where jurisprudence and bioethical discourse were argued to have a curious relationship with aesthetic concerns, and in particular metaphors or tropes, when it came to arguing either for, or against, abortion (Jones 2013). In essence, the urgency of representational strategies has not ceased to be an integral sticking-point in arguing for or against abortion legislation and permissibility, and there are many ways, both research-based and more 'practically' to explore this. While my doctoral research project took this possibility into the domain of nineteenth century poetry, the insights that emerged from the investigation sparked a felt need to turn to the possibilities, and limitations, of representing abortion rights within contemporary visual art, and how this might, or might not, have a place alongside more direct critique and action.

Hanging $O n$ in effect owes a great debt to the work of several, key feminist scholars and their interrogation of the relationship between abortion and aesthetics. Drucilla Cornell's notion of the need to rethink the female imaginary domain and that feminist legal reform "cannot proceed without the re-imagining and the resymbolisation of the feminine within sexual difference which takes back 'ourselves' from the masculine imaginary" (Cornell 1995a, 50) remains a striking statement to me. In particular Cornell explains the significance of analogy in the desire to defend the right to abortion in contemporary discourse: "the search began to find ways to argue that pregnancy was analogous to some engendered condition in men. The analogies never seemed to work" (Cornell 1995a, 61). Finally for Cornell, this means that the woman must be the "arbiter of meaning of her act to abort" (Cornell 1995b, 61) (an issue contingent on representational authority that we will return to shortly as problematic when producing this visual piece). Any reservations towards Cornell's thesis aside, this approach clearly opens up a viable

\footnotetext{
1 The FLaK Seminar: Mixing Feminism, Legality and Knowledge, 30 June-20 July 2016, held at Queen Mary University of London. See http://www.law.qmul.ac.uk/events/items/167540.html for further information and Fletcher (2015) and Fletcher et al. (2017).
} 


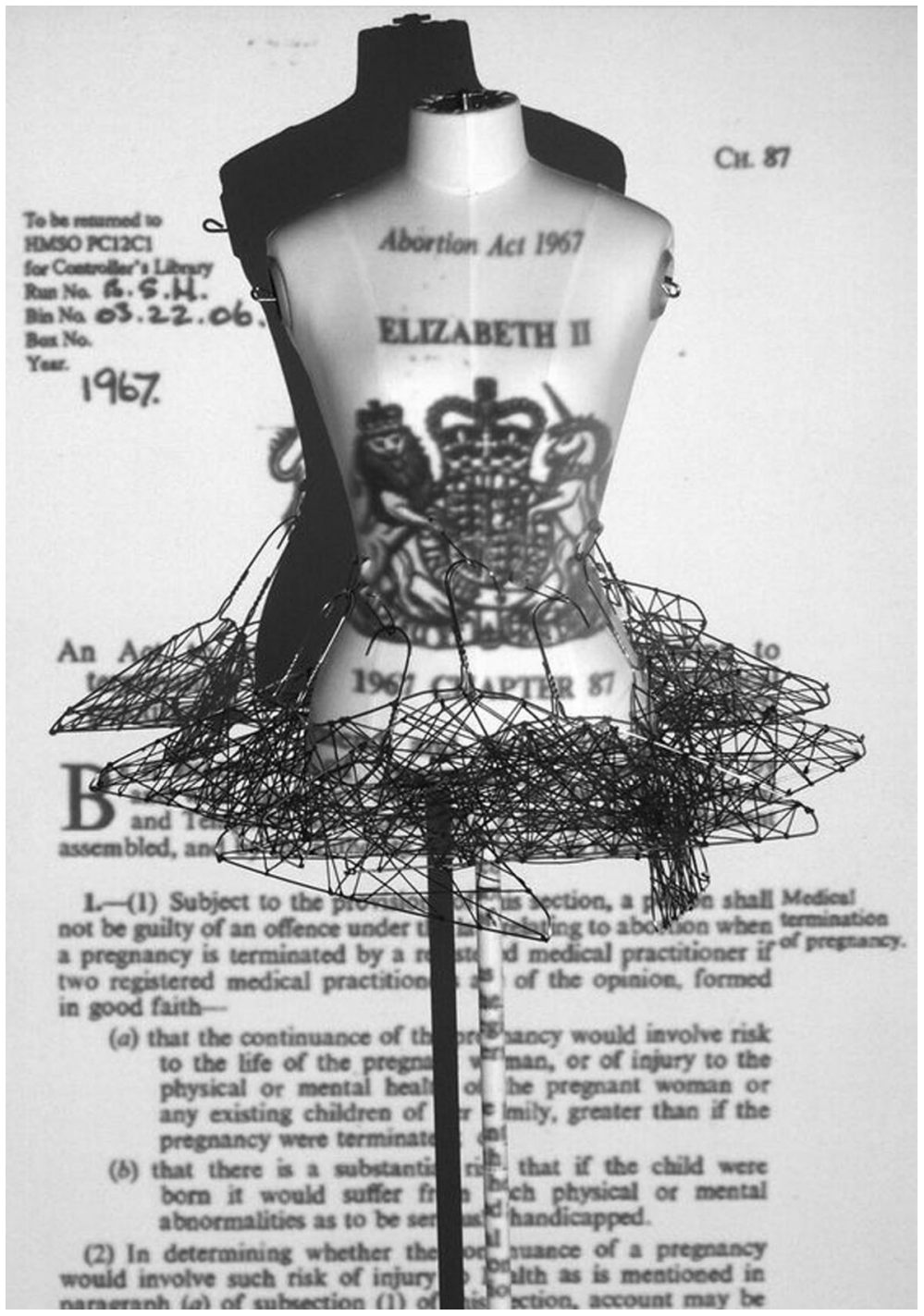

Fig. 1 The page produced by Natalie ${ }^{2}$ for the 'At the Kitchen Table' zine, which was launched at the FLaK seminar on 30th June 2016. Natalie ${ }^{2}$ is a multimedia, visual arts initiative led by Dr Natalie Shona Hart and Dr Natalie Linda Jones, who are academics and practising artists working in a socially-engaged partner collective. The page is reproduced here with their permission

space to value the realm of representation in abortion discourse. ${ }^{2}$ For Hanging On, this theoretical premise sparked a challenge to think about a specific form of

\footnotetext{
${ }^{2}$ Although Cornell's argument is focused more on the 'imaginary domain' as a specifically psychic space, related to Lacanian ideas of bodily integrity and symbolisation, Cornell's chapter on abortion does use literary fiction in order to explore the import of aesthetic factors within the symbolisation of this 'domain', while considering analogy and the 'imaginary' as crucial to reframing the impasse of the debate.
} 
feminist knowledge production being enacted within the piece. More directly, the work of Laurie Shrage in "From Reproductive Rights to Reproductive Barbie: PostPorn Modernism and Abortion" threw a hypothetical gauntlet to pro-choice advocates, invoking the need to address the concession of the visual and cultural domain in the struggle to assert the legitimacy of abortion (Shrage 2002). Shrage provides a cogent summary of the visual propaganda used by anti-abortion activists, and outlines a strategy (replete with concrete examples) of how 'pro-choice' advocates can begin to recover the cultural ground conceded to the anti-abortion camp.

Shrage's work on the potential for visual symbolism and politically-informed artwork to counter the reductive-and negative-cultural representations of abortion made for a thought-provoking visual call-to-arms. More specifically within the context of feminism and law, the work of Rosalind Petchesky (1990) and Margaret Olivia Little (1999) was equally integral in raising the possibility of challenging conventional conceptualisations of unwanted pregnancy, and abortion. In many ways, the act of 'translating' such ideas into visual art may seem an act of 'transgression'. But art, of course, has ever turned on the privilege of daring to tread across legitimised boundaries, and offer explorations of issues seemingly beyond the pale, however uncomfortable or shocking these might be. For Hanging On, however, the concern was in fact contrary to any apprehension of disciplinary transgression, or 'betrayal'. Instead, the key challenge lay in the attempt to be faithful to the agenda that precipitated the piece. Formidable and striking artwork already exists that hinges on the horrors of a lack of access to safe, legal abortion (see, for example, Paula Rego's Abortion Series, 1998-1999³), but how to represent and celebrate the legal availability of abortion and its coding within UK law without recourse to an aesthetics of negativity? Shrage, after all, emphasizes how striking it is that so many critics focus solely on unwanted pregnancy, while paying little attention to the representation of abortion. In other words, while critiquing the maternal ideology that valorizes pregnancy at the expense of the woman's attribution of meaning, some critics then focus explicitly on the experience of unwanted pregnancy at the expense of formulating the meaning of abortion.

In many ways this tension played itself out visually in the final piece that was constructed, and in its photographic image, for the Zine. But it was a tension that marked a valuable experience of feminist knowledge production, not to mention the difficulties of negotiating the relationship between theoretical premises, political agendas, and art production. Because Hanging On did of course set out with a political agenda, or at least affiliation-in asserting the legitimacy of the legal right to abort. Space does not allow an extended discussion here of the consequent issue of art's autonomy versus propaganda (a question I'm sure will be a lifelong tension within my artwork, and underpins my ongoing academic research), but in searching for visual 'markers' to communicate the value of the UK Abortion Act 1967, the piece did undoubtedly confront the same 'limitations' described by scholars such as

\footnotetext{
3 For a discussion of this work see Strøm (2004) and the following interview with Paula Rego by Mick Brown (2008) available at http://www.telegraph.co.uk/culture/art/6469383/Paula-Rego-interview.html. Accessed 31 October 2017.
} 
Cornell and Shrage. At a basic level, Cornell's premise that women who abort should be the arbiters of meaning raises the thorny question of who does have the authority to make this kind of visual work. But then this could be asked of any piece of creative work where an artist may or may not be exploring an issue directly experienced by, and relevant to, themselves. More difficult to overcome, in fact, was Shrage's highlighting of the concentration on unwanted pregnancy. How to disentangle this phenomenon in favour of the positive strides begun by the 1967 Act? The decision to use coat hangers, therefore, was a laboured choice. Frequently re-appropriated as an empowering symbol by many pro-choice campaign groups, it has been critiqued for its connotations of negativity, not to mention accuracy, in terms of how common this practice actually was. ${ }^{4}$ But as a powerful symbol it in many ways spoke to the ethos of the piece. A female mannequin having been found by the work's visual co-collaborator, Dr Natalie Hart, on a local street in previous weeks, it was immediately clear that this could offer a powerful starting-point for the work, and the relationship between mannequins, the textiles industry and female bodily authority became immediately apparent. My own visual practice as a solo artist, meanwhile, already incorporated a textiles-based threading technique using red thread, and while the decision to incorporate my textiles-based technique was itself a cause for reflection (a reading of this technique could easily slide into reductive, and since challenged, connotations of gendered divisions in artistic disciplines), as a visual principle it lent itself to the deeper theoretical issues of entanglement between the body, authority and legality that the piece was encountering. But in the final installation, the image played on an evocative palimpsest between the literal, visual marker of the 1967 Act, projected onto the mannequin's body, and the threaded hangers that are overlaid, disturbing the boundaries between visual symbolism and concrete action.

Perhaps the piece does finally question the extent to which we can divide unwanted pregnancy in the context of a lack of access to abortion from the representation of abortion itself. And perhaps now more than ever that coupling, or correlation, is returning to the forefront of very real, legal concerns. But I think that what really directed the tone of the piece is that it is in a sense a representation of British collective memory within the legal domain, and the memory embedded within the Act is undoubtedly linked to a deeper historical truth that should not be forgotten. Moving forward, my own solo artwork will endeavour to find alternative, less ambiguous modes of positive expression of abortion, but in the context of FLaK, the need to take stock before moving forward felt appropriate. The larger question, however, of the overall impact of such creative interventions and interpretations of feminist knowledge must, for later historical discussion, be left hanging.

\footnotetext{
${ }^{4}$ See the following online article for further discussion https://thinkprogress.org/the-coat-hanger-comesof-age-c592682a987\#.1ozu7f5d3, and also https://www.theguardian.com/commentisfree/2015/dec/15/ wire-coat-hanger-abortion-stories-united-states, as well as https://www.nytimes.com/2016/03/06/ opinion/sunday/the-return-of-the-diy-abortion.html?_r=0 for a consideration of the continuation of this practice in the United States. Accessed 31 October 2017.
} 
Open Access This article is distributed under the terms of the Creative Commons Attribution 4.0 International License (http://creativecommons.org/licenses/by/4.0/), which permits unrestricted use, distribution, and reproduction in any medium, provided you give appropriate credit to the original author(s) and the source, provide a link to the Creative Commons license, and indicate if changes were made.

\section{References}

Brown, Mick. 2008. Interview with Paula Rego. The Telegraph. 4 November. Available at http://www. telegraph.co.uk/culture/art/6469383/Paula-Rego-interview.html.

Butler, Judith. 2011. Bodies That Matter: On the Discursive Limits of "Sex". New York and London: Routledge.

Cornell, Drucilla. 1995a. The Imaginary Domain: Abortion, Pornography and Sexual Harassment. New York and London: Routledge.

Cornell, Drucilla. 1995b. To the Editors. Boston Review. October-November.

Fletcher, Ruth. 2015. FLaK: Mixing Feminism, Legality and Knowledge. Feminist Legal Studies 23(3): 241-252.

Fletcher, Ruth, et al. 2017. Wench Tactics? Openings in Conditions of Closure. Feminist Legal Studies 25(1): 1-23.

Jones, Natalie Linda. 2013. The Abortion Trope: A Study in Contemporary Criticism and NineteenthCentury Poetics, Ph.D. Thesis University of Birmingham. http://etheses.bham.ac.uk/4419/.

Little, Margaret Olivia. 1999. Abortion, Intimacy, and the Duty to Gestate. Ethical Theory and Moral Practice 2: 295-312.

Petchesky, Rosalind. 1990. Abortion and Women's Choice: The State, Sexuality, and Reproductive Freedom. Michigan: Northeastern University Press.

Rego, Paula. 1998-1999. Untitled: The Abortion Pastels. Pastels and Etchings: Various locations.

Shrage, Laurie. 2002. From Reproductive Rights to Reproductive Barbie: Post-Porn Modernism and Abortion. Feminist Studies 28(1): 61-93.

Strøm, Agnete. 2004. "Untitled: The Abortion Pastels": Paula Rego's Series on Abortion. Reproductive Health Matters 12(24): 195-197. 